\title{
The Futures of Digital Libraries: The Evolution of an Idea
}

\author{
Clifford Lynch \\ Coalition for Networked Information
}

\begin{abstract}
The construction of digital libraries have certainly framed technological challenges, particularly with regard to various aspects of scale, and with the complexities of dealing with human languages, and indeed have given rise to substantial progress in these and other technical fields. But I believe that the greatest significance of digital libraries has been at a more profound intellectual level, inviting us to envision new kinds of environments for knowledge discovery, formulation, and dissemination; approaches to defining, managing and interacting with the cultural and intellectual record of our societies. We have repeatedly been forced to revisit questions of what constitutes a digital library, and how (indeed, even if) this differs from simply a collection of digitized or born-digital materials.

In my presentation I will look at some of there recent responses of these challenges of vision, examining emerging systems like Europeana and proposals like the Digital Public Library of America, a few well established operational digital libraries in various sectors, developing scientific knowledge management environments that integrate scholarship, scholarly communication and evidence, and even the changing ways in which we think of the collective mass of information available worldwide through the internet. As part of my analysis, I will discuss the enormous distorting effects of current copyright laws on our ability to realize many of our collective visions and to achieve necessary scale, but also the promise offered by the new renaissance in public engagement (citizen science, social media and related developments) and the progress of various movements towards openness. Finally, as I look to the conceptual future of digital libraries I'll consider the steady advance of technological capabilities in the analysis and exploitation of large, dynamic corpora of materials; these will also continue to reshape our understanding of future directions and possibilities.
\end{abstract}

